\title{
Fixed point theorems for generalized contractions on GP-metric spaces
}

\author{
Nurcan Bilgili', Erdal Karapınar ${ }^{2 *}$ and Peyman Salimi ${ }^{3}$
}

"Correspondence:

erdalkarapinar@yahoo.com;

ekarapinar@atilim.edu.tr

${ }^{2}$ Department of Mathematics,

Atilim University, Incek, Ankara 06836, Turkey

Full list of author information is available at the end of the article

\begin{abstract}
In this paper, we present two fixed point theorems on mappings, defined on GP-complete GP-metric spaces, which satisfy a generalized contraction property determined by certain upper semi-continuous functions. Furthermore, we illustrate applications of our theorems with a number of examples. Inspired by the work of Jachymski, we also establish equivalences of certain auxiliary maps in the context of GP-complete GP-metric spaces.
\end{abstract}

MSC: $47 \mathrm{H} 10 ; 54 \mathrm{H} 25$

Keywords: fixed point; partial metric space; GP-metric space

\section{Introduction and preliminaries}

In 1922, Stefan Banach [1] stated his celebrated theorem on the existence and uniqueness of a fixed point of certain self-maps defined on certain metric spaces for the first time. Specifically, this elegant theorem, also known as the Banach contraction mapping principle, can be formulated as follows: any mapping $T:(X, d) \rightarrow(X, d)$ has a unique point $x \in X$ such that $T x=x$ provided that there exists a constant $k \in(0,1)$ satisfying the inequality $d(T x, T y) \leq k d(x, y)$ for every $x, y \in X$, where $(X, d)$ is a complete metric space. A mapping $T$ for which the inequality mentioned above holds is called a contraction.

Since its first appearance, the Banach contraction mapping principle has become the main tool to study contractions as they appear abundantly in a wide array of quantitative sciences. Its most well-known application is in ordinary differential equations, particularly, in the proof of the Picard-Lindelöf theorem which guarantees the existence and uniqueness of solutions of first-order initial value problems. It is worth emphasizing that the remarkable strength of the Banach principle originates from the constructive process it provides to identify the fixed point. This notable strength further attracted the attention of not only many prominent mathematicians studying in many branches of mathematics related to nonlinear analysis, but also many researchers who are interested in iterative methods to examine the quantitative problems involving certain mappings and space structures required in their work in various areas such as social sciences, biology, economics, and computer sciences.

Indeed, in 1994, Matthews, a computer scientist who is an expert on semantics, announced in [2] an analog of Banach's principle in a new space he called a partial metric space. Matthews's innovative approach was quickly adopted and improved by fixed point theorists (see, e.g., [3-27]) with the aim of discovering analogs of Banach's principle in 
the context of partial metric spaces to broaden its applications and enrich the fixed point theory as a result.

A closer look to the work of these distinguished mathematicians after Matthews's studies reveals that their discoveries can be categorized in terms of the techniques implemented to produce the analogs of Banach's principle. The first technique is to introduce new space structures with certain properties which guarantee the existence and/or uniqueness of fixed points of contractions. In addition to Matthews's investigations, cone metric spaces, $D$-metric spaces, and G-metric spaces (see, e.g., [28-44]) constitute a few of the examples to the first approach. The second technique is to introduce mappings defined on metric spaces satisfying certain new contractive conditions. For example, cyclic contractions and weak $\phi$ contractions can be listed as a few.

As another example to the first approach mentioned above, Zand and Nezhad [43] recently introduced GP-metric spaces which are a combination of the notions of partial metric spaces and G-metric spaces. Then they proved a number of fixed point theorems on these new spaces for certain type of contractions. In this paper, we exercise the second approach by using the space structure they initiated to prove certain fixed point theorems for generalized contractions. First, we review the necessary notation, definitions, and fundamental results produced on GP-metric spaces that we will need in this work.

Definition 1.1 [43] Let $X$ be a non-empty set. A function $G_{p}: X \times X \times X \rightarrow[0,+\infty)$ is called a $G P$-metric if the following conditions are satisfied:

(GP1) $x=y=z$ if $G_{p}(x, y, z)=G_{p}(z, z, z)=G_{p}(y, y, y)=G_{p}(x, x, x)$;

(GP2) $0 \leq G_{p}(x, x, x) \leq G_{p}(x, x, y) \leq G_{p}(x, y, z)$ for all $x, y, z \in X$;

(GP3) $G_{p}(x, y, z)=G_{p}(x, z, y)=G_{p}(y, z, x)=\cdots$, symmetry in all three variables;

(GP4) $G_{p}(x, y, z) \leq G_{p}(x, a, a)+G_{p}(a, y, z)-G_{p}(a, a, a)$ for any $x, y, z, a \in X$.

Then the pair $(X, G)$ is called a $G P$-metric space.

Example 1.1 [43] Let $X=[0, \infty)$ and define $G_{p}(x, y, z)=\max \{x, y, z\}$ for all $x, y, z \in X$. Then $\left(X, G_{p}\right)$ is a $G P$-metric space.

Proposition 1.1 [43] Let $\left(X, G_{p}\right)$ be a GP-metric space, then for any $x, y, z$ and $a \in X$, it follows that

(i) $G_{p}(x, y, z) \leq G_{p}(x, x, y)+G_{p}(x, x, z)-G_{p}(x, x, x)$;

(ii) $G_{p}(x, y, y) \leq 2 G_{p}(x, x, y)-G_{p}(x, x, x)$;

(iii) $G_{p}(x, y, z) \leq G_{p}(x, a, a)+G_{p}(y, a, a)+G_{p}(z, a, a)-2 G_{p}(a, a, a)$;

(iv) $G_{p}(x, y, z) \leq G_{p}(x, a, z)+G_{p}(a, y, z)-G_{p}(a, a, a)$.

Proposition 1.2 [43] Every GP-metric space $\left(X, G_{p}\right)$ defines a metric space $\left(X, D_{G_{p}}\right)$ where

$$
D_{G_{p}}(x, y)=G_{p}(x, y, y)+G_{p}(y, x, x)-G_{p}(x, x, x)-G_{p}(y, y, y) \quad \text { for all } x, y \in X \text {. }
$$

Definition 1.2 [43] Let $\left(X, G_{p}\right)$ be a $G P$-metric space and let $\left\{x_{n}\right\}$ be a sequence of points of $X$. A point $x \in X$ is said to be the limit of the sequence $\left\{x_{n}\right\}$ or $x_{n} \rightarrow x$ if

$$
\lim _{n, m \rightarrow \infty} G_{p}\left(x, x_{m}, x_{n}\right)=G_{p}(x, x, x)
$$


Proposition 1.3 [43] Let $\left(X, G_{p}\right)$ be a GP-metric space. Then, for any sequence $\left\{x_{n}\right\}$ in $X$ and a point $x \in X$, the following are equivalent:

(A) $\left\{x_{n}\right\}$ is GP-convergent to $x$;

(B) $G_{p}\left(x_{n}, x_{n}, x\right) \rightarrow G_{p}(x, x, x)$ as $n \rightarrow \infty$;

(C) $G_{p}\left(x_{n}, x, x\right) \rightarrow G_{p}(x, x, x)$ as $n \rightarrow \infty$.

Definition 1.3 [43] Let $\left(X, G_{p}\right)$ be a GP-metric space.

(S1) A sequence $\left\{x_{n}\right\}$ is called a GP-Cauchy if and only if $\lim _{m, n \rightarrow \infty} G_{p}\left(x_{n}, x_{m}, x_{m}\right)$ exists (and is finite);

(S2) A GP-partial metric space $\left(X, G_{p}\right)$ is said to be $G P$-complete if and only if every $G P$-Cauchy sequence in $X$ is GP-convergent to $x \in X$ such that $G_{p}(x, x, x)=\lim _{m, n \rightarrow \infty} G_{p}\left(x_{n}, x_{m}, x_{m}\right)$.

Now, we introduce the following.

Definition 1.4 Let $\left(X, G_{p}\right)$ be a $G P$-metric space.

(M1) A sequence $\left\{x_{n}\right\}$ is called 0-GP-Cauchy if and only if $\lim _{m, n \rightarrow \infty} G_{p}\left(x_{n}, x_{m}, x_{m}\right)=0$;

(M2) A GP-metric space $\left(X, G_{p}\right)$ is said to be 0 -GP-complete if and only if every

0 -GP-Cauchy sequence in $X G P$-converges to a point $x \in X$ such that $G_{p}(x, x, x)=0$.

Example 1.2 Let $X=[0,+\infty)$ and define $G_{p}(x, y, z)=\max \{x, y, z\}$ for all $x, y, z \in X$. Then $\left(X, G_{p}\right)$ is a $G P$-complete $G P$-metric space. Moreover, if $X=\mathbb{Q} \cap[0,+\infty)$ (where $\mathbb{Q}$ denotes a set of rational numbers), then $\left(X, G_{p}\right)$ is a $0-G P$-complete $G P$-metric space.

Lemma 1.1 (See [45]) Let $\left(X, G_{p}\right)$ be a GP-metric space. Then

(A) If $G_{p}(x, y, z)=0$, then $x=y=z$;

(B) If $x \neq y$, then $G_{p}(x, y, y)>0$.

In the rest of this paper, we will denote the positive natural numbers by $\mathbb{N}^{*}$ and the natural numbers by $\mathbb{N}$.

\section{Main results}

In this section, we present our findings on fixed point theorems on 0-GP-complete GPmetric spaces. We first start with the following definition.

Definition 2.1 Let $\left(X, G_{p}\right)$ be a $G P$-metric space and $T:\left(X, G_{p}\right) \rightarrow\left(X, G_{p}\right)$ be a map. Let $M(x, y, y)$ denote the value

$$
\max \left\{G_{p}(x, y, y), G_{p}(x, T x, T x), G_{p}(y, T y, T y), \frac{1}{2}\left[G_{p}(x, T y, T y)+G_{p}(y, T x, T x)\right]\right\}
$$

for all $x, y \in X$.

Lemma 2.1 If $\left(X, G_{p}\right)$ is a GP-metric space and $T: X \rightarrow X$ is a map, then, for each $x \in X$, we have

$$
M(x, T x, T x)=\max \left\{G_{p}(x, T x, T x), G_{p}\left(T x, T^{2} x, T^{2} x\right)\right\} .
$$


Proof Let $x \in X$. Then

$$
\begin{aligned}
\max & \left\{G_{p}(x, T x, T x), G_{p}\left(T x, T^{2} x, T^{2} x\right)\right\} \\
\leq & M(x, T x, T x) \\
= & \max \left\{G_{p}(x, T x, T x), G_{p}(x, T x, T x), G_{p}\left(T x, T^{2} x, T^{2} x\right),\right. \\
& \left.\frac{1}{2}\left[G_{p}\left(x, T^{2} x, T^{2} x\right)+G_{p}(T x, T x, T x)\right]\right\} \\
\leq & \max \left\{G_{p}(x, T x, T x), G_{p}(x, T x, T x), G_{p}\left(T x, T^{2} x, T^{2} x\right),\right. \\
& \left.\frac{1}{2}\left[G_{p}(x, T x, T x)+G_{p}\left(T x, T^{2} x, T^{2} x\right)\right]\right\} \\
= & \max \left\{G_{p}(x, T x, T x), G_{p}\left(T x, T^{2} x, T^{2} x\right)\right\} .
\end{aligned}
$$

The proof is complete.

Lemma 2.2 Let $\left(X, G_{p}\right)$ be a GP-metric space and let $T: X \rightarrow X$ be a map such that

$$
G_{p}(T x, T y, T y) \leq \phi(M(x, y, y))
$$

for all $x, y \in X$, where $\phi:[0, \infty) \rightarrow[0, \infty)$ is a function such that $\phi(t)<t$ for all $t>0$. If $x \in X$ satisfies $T^{n} x \neq T^{n+1} x$ for all $n \in \mathbb{N}$, then the following hold:

(a) $M\left(T^{n} x, T^{n+1} x, T^{n+1} x\right)=G_{p}\left(T^{n} x, T^{n+1} x, T^{n+1} x\right)$ for all $n \in \mathbb{N}$;

(b) $G_{p}\left(T^{n} x, T^{n+1} x, T^{n+1} x\right) \leq \phi\left(G_{p}\left(T^{n-1} x, T^{n} x, T^{n} x\right)\right)<G_{p}\left(T^{n-1} x, T^{n} x, T^{n} x\right)$ for all $n \in \mathbb{N}^{*}$.

Proof (a) From Lemma 2.1, we have

$$
M\left(T^{n} x, T^{n+1} x, T^{n+1} x\right)=\max \left\{G_{p}\left(T^{n} x, T^{n+1} x, T^{n+1} x\right), G_{p}\left(T^{n+1} x, T^{n+2} x, T^{n+2} x\right)\right\} .
$$

Since $T^{n} x \neq T^{n+1} x$ for all $n \in \mathbb{N}$, then by Lemma 1.1(B), we get $G_{p}\left(T^{n} x, T^{n+1} x, T^{n+1} x\right)>0$ for all $n \in \mathbb{N}$. Consequently, $M\left(T^{n} x, T^{n+1} x, T^{n+1} x\right)>0$. Now by condition (4), we deduce that

$$
\begin{aligned}
G_{p}\left(T^{n+1} x, T^{n+2} x, T^{n+2} x\right) & \leq \phi\left(M\left(T^{n} x, T^{n+1} x, T^{n+1} x\right)\right) \\
& <M\left(T^{n} x, T^{n+1} x, T^{n+1} x\right),
\end{aligned}
$$

that is, $G_{p}\left(T^{n+1} x, T^{n+2} x, T^{n+2} x\right)<G_{p}\left(T^{n} x, T^{n+1} x, T^{n+1} x\right)$. Hence, (a) holds.

Clearly, (b) follows from (4), (a), and the fact that $G_{p}\left(T^{n-1} x, T^{n} x, T^{n} x\right)>0$ for all $n \in \mathbb{N}$.

Definition 2.2 A function $\phi:[0, \infty) \rightarrow[0, \infty)$ is called upper semi-continuous from the right if for each $t \geq 0$ and each sequence $\left(t_{n}\right)_{n \in \mathbb{N}^{*}}$ such that $t_{n} \geq t$ and $\lim _{n \rightarrow \infty} t_{n}=t$, the equality holds lim $\sup _{n \rightarrow \infty} \phi\left(t_{n}\right) \leq \phi(t)$. 
Theorem 2.1 Let $\left(X, G_{p}\right)$ be a GP-complete GP-metric space and let $T: X \rightarrow X$ be a map such that

$$
G_{p}(T x, T y, T y) \leq \phi(M(x, y, y))
$$

for all $x, y \in X$, where $\phi:[0, \infty) \rightarrow[0, \infty)$ is an upper semi-continuous function from the right such that $\phi(t)<t$ for all $t>0$. Then $T$ has a unique fixed point $z \in X$. Moreover, $G_{p}(z, z, z)=0$.

Proof Let $x \in X$. If there is $n \in \mathbb{N}$ such that $T^{n} x=T^{n+1} x$, then $T^{n} x$ is a fixed point of $T$ and the uniqueness of $T^{n} x$ follows as in the last part of the proof below. Hence, we assume that $T^{n} x \neq T^{n+1} x$ for all $n \in \mathbb{N}$. Put $x_{0}=x$ and construct the sequence $\left(x_{n}\right)_{n \in \mathbb{N}}$, where $x_{n}=T^{n} x_{0}$ for all $n \in \mathbb{N}$. Thus, $x_{n+1}=T x_{n}$ and $G_{p}\left(x_{n}, x_{n+1}, x_{n+1}\right)>0$ for all $n \in \mathbb{N}$. Define the sequence $\left\{s_{n}\right\}$ by $s_{n}=G_{p}\left(x_{n}, x_{n+1}, x_{n+1}\right)$ for all $n \in \mathbb{N}$. From Lemma $2.2(\mathrm{~b})$ we know that $\left\{s_{n}\right\}$ is a nonincreasing sequence. Hence, there exists $c \in \mathbb{R}^{+}$such that $s_{n} \rightarrow c$ as $n \rightarrow \infty$. We will show that $c$ must be equal to 0 . Let $c>0$. By taking limitsup as $n \rightarrow \infty$ in condition (b) of Lemma 2.2, we get that

$$
c=\limsup _{n \rightarrow \infty} G_{p}\left(x_{n}, x_{n+1}, x_{n+1}\right)=\limsup _{n \rightarrow \infty} \phi\left(G_{p}\left(x_{n}, x_{n+1}, x_{n+1}\right)\right)
$$

and so, by upper semi-continuity from the right of the function $\phi$, we deduce

$$
c=\limsup _{n \rightarrow \infty} \phi\left(G_{p}\left(x_{n}, x_{n+1}, x_{n+1}\right)\right) \leq \phi(c)<c,
$$

which is a contradiction. Hence, $c=0$. Consequently, $\lim _{n \rightarrow \infty} G_{p}\left(x_{n}, x_{n+1}, x_{n+1}\right)=0$. Next we show that $\lim _{n, m \rightarrow \infty} G_{p}\left(x_{n}, x_{m}, x_{m}\right)=0$. Assume the contrary. Then there exist $\varepsilon>0$ and sequences $\left(n_{k}\right)_{k \in \mathbb{N}^{*}},\left(m_{k}\right)_{k \in \mathbb{N}^{*}}$ in $\mathbb{N}^{*}$ with $m_{k} \geq n_{k} \geq k$ and such that $G_{p}\left(x_{n_{k}}, x_{m_{k}}, x_{m_{k}}\right) \geq \varepsilon$ for all $k \in \mathbb{N}^{*}$. From the fact that $\lim _{n \rightarrow \infty} G_{p}\left(x_{n}, x_{n+1}, x_{n+1}\right)=0$, we can suppose, without loss of generality, that $G_{p}\left(x_{n_{k}}, x_{m_{k}-1}, x_{m_{k}-1}\right)<\varepsilon$. For each $k \in \mathbb{N}^{*}$, we have

$$
\begin{aligned}
\varepsilon & \leq G_{p}\left(x_{n_{k}}, x_{m_{k}}, x_{m_{k}}\right) \leq G_{p}\left(x_{n_{k}}, x_{m_{k}-1}, x_{m_{k}-1}\right)+G_{p}\left(x_{m_{k}-1}, x_{m_{k}}, x_{m_{k}}\right) \\
& <\varepsilon+G_{p}\left(x_{m_{k}-1}, x_{m_{k}}, x_{m_{k}}\right)
\end{aligned}
$$

and hence $\lim _{k \rightarrow \infty} G_{p}\left(x_{n_{k}}, x_{m_{k}}, x_{m_{k}}\right)=\varepsilon$. Now, let $k_{0} \in \mathbb{N}^{*}$ be such that $G_{p}\left(x_{n_{k}}, x_{n_{k}+1}, x_{n_{k}+1}\right)<$ $\varepsilon$ and $G_{p}\left(x_{m_{k}}, x_{m_{k}+1}, x_{m_{k}+1}\right)<\varepsilon$ for all $k \geq k_{0}$. Then

$$
\begin{aligned}
G_{p}\left(x_{n_{k}}, x_{m_{k}}, x_{m_{k}}\right) \leq & M\left(x_{n_{k}}, x_{m_{k}}, x_{m_{k}}\right) \\
= & \max \left\{G_{p}\left(x_{n_{k}}, x_{m_{k}}, x_{m_{k}}\right), G_{p}\left(x_{n_{k}}, x_{n_{k}+1}, x_{n_{k}+1}\right),\right. \\
& G_{p}\left(x_{m_{k}}, x_{m_{k}+1}, x_{m_{k}+1}\right), \\
& \left.\frac{1}{2}\left[G_{p}\left(x_{n_{k}}, x_{m_{k}+1}, x_{m_{k}+1}\right)+G_{p}\left(x_{m_{k}}, x_{n_{k}+1}, x_{n_{k}+1}\right)\right]\right\} \\
\leq & \max \left\{G_{p}\left(x_{n_{k}}, x_{m_{k}}, x_{m_{k}}\right), G_{p}\left(x_{n_{k}}, x_{n_{k}+1}, x_{n_{k}+1}\right),\right. \\
& G_{p}\left(x_{m_{k}}, x_{m_{k}+1}, x_{m_{k}+1}\right),
\end{aligned}
$$




$$
\begin{aligned}
& \frac{1}{2}\left[G_{p}\left(x_{n_{k}}, x_{n_{k}+1}, x_{n_{k}+1}\right)+G_{p}\left(x_{n_{k}+1}, x_{n_{k}+2}, x_{n_{k}+2}\right)+\cdots\right. \\
& +G_{p}\left(x_{m_{k}}, x_{m_{k}+1}, x_{m_{k}+1}\right)+G_{p}\left(x_{m_{k}}, x_{m_{k}-1}, x_{m_{k}-1}\right) \\
& \left.\left.+G_{p}\left(x_{m_{k}-1}, x_{m_{k}-2}, x_{m_{k}-2}\right)+\cdots+G_{p}\left(x_{n_{k}+2}, x_{n_{k}+1}, x_{n_{k}+1}\right)\right]\right\}
\end{aligned}
$$

for all $k \geq k_{0}$. So, $\lim _{k \rightarrow \infty} M\left(x_{n_{k}}, x_{m_{k}}, x_{m_{k}}\right)=\varepsilon$. Since $M\left(x_{n_{k}}, x_{m_{k}}, x_{m_{k}}\right) \geq \varepsilon$ for all $k \in \mathbb{N}^{*}$ and $\phi$ is upper semi-continuous from the right, we deduce that $\limsup _{k \rightarrow \infty} \phi\left(M\left(x_{n_{k}}\right.\right.$, $\left.\left.x_{m_{k}}, x_{m_{k}}\right)\right) \leq \phi(\varepsilon)$. On the other hand, for each $k \in \mathbb{N}^{*}$, we have

$$
\begin{aligned}
\varepsilon \leq & G_{p}\left(x_{n_{k}}, x_{m_{k}}, x_{m_{k}}\right) \leq G_{p}\left(x_{n_{k}}, x_{n_{k}+1}, x_{n_{k}+1}\right)+G_{p}\left(x_{n_{k}+1}, x_{m_{k}+1}, x_{m_{k}+1}\right) \\
& +G_{p}\left(x_{m_{k}+1}, x_{m_{k}}, x_{m_{k}}\right) \\
\leq & G_{p}\left(x_{n_{k}}, x_{n_{k}+1}, x_{n_{k}+1}\right)+\phi\left(M\left(x_{n_{k}}, x_{m_{k}}, x_{m_{k}}\right)\right) \\
& +G_{p}\left(x_{m_{k}+1}, x_{m_{k}}, x_{m_{k}}\right),
\end{aligned}
$$

so $\varepsilon \leq \limsup _{k \rightarrow \infty} \phi\left(M\left(x_{n_{k}}, x_{m_{k}}, x_{m_{k}}\right)\right) \leq \phi(\varepsilon)$, a contradiction because $\phi(\varepsilon)<\varepsilon$. Consequently, $\lim _{n, m \rightarrow \infty} G_{p}\left(x_{n}, x_{m}, x_{m}\right)=0$ and thus $\left(x_{n}\right)_{n \in \mathbb{N}}$ is a Cauchy sequence in the GPcomplete $G P$-metric space $\left(X, G_{p}\right)$. Hence, there is $z \in X$ such that

$$
\lim _{n, m \rightarrow \infty} G_{p}\left(x_{n}, x_{m}, x_{m}\right)=\lim _{n \rightarrow \infty} G_{p}\left(z, x_{n}, x_{n}\right)=G_{p}(z, z, z)=0 .
$$

We show that $z$ is a fixed point of $T$. To this end, we first note that $G_{p}(z, T z, T z)=$ $\lim _{n \rightarrow \infty} M\left(z, x_{n}, x_{n}\right)$, so $\lim \sup _{n \rightarrow \infty} \phi\left(M\left(z, x_{n}, x_{n}\right)\right) \leq \phi\left(G_{p}(z, T z, T z)\right)$. On the other hand, since for each $n \in \mathbb{N}, G_{p}(z, T z, T z) \leq G_{p}\left(z, x_{n}, x_{n}\right)+G_{p}\left(x_{n}, T z, T z\right)$, it follows that

$$
\begin{aligned}
G_{p}(z, T z, T z) & \leq \limsup _{n \rightarrow \infty}\left(G_{p}\left(z, x_{n}, x_{n}\right)+G_{p}\left(x_{n}, T z, T z\right)\right) \\
& =\limsup _{n \rightarrow \infty} G_{p}\left(x_{n}, T z, T z\right) \\
& \leq \limsup _{n \rightarrow \infty} \phi\left(M\left(x_{n-1}, z, z\right)\right) \\
& \leq \phi\left(G_{p}(z, T z, T z)\right) .
\end{aligned}
$$

Therefore, $G_{p}(z, T z, T z)=0$ and thus $z=T z$. Finally, let $u \in X$ be such that $T u=u$. Then

$$
G_{p}(u, z, z)=G_{p}(T u, T z, T z) \leq \phi(M(u, z, z))=\phi\left(G_{p}(u, z, z)\right) .
$$

Hence, $G_{p}(u, z, z)=0$, i.e., $u=z$. This concludes the proof.

Definition 2.3 Let $\psi(\cdot, \cdot): X \times X \rightarrow[0, \infty)$ be a given function. Then $Q(x, y, z)$ will denote the value

$$
\begin{aligned}
& \max \left\{G_{p}(x, y, z), G_{p}(x, T x, T x), G_{p}(y, T y, T y), G_{p}(z, T z, T z),\right. \\
& \left.\frac{1}{2}\left[G_{p}(x, T y, T y)+G_{p}(y, T x, T x)\right], \frac{1}{2}\left[G_{p}(x, T z, T z)+G_{p}(z, T x, T x)\right]\right\} .
\end{aligned}
$$


Then we obtain the following statement.

Corollary 2.1 Let $\left(X, G_{p}\right)$ be a GP-complete GP-metric space and let $T: X \rightarrow X$ be a map such that

$$
\begin{aligned}
0 \leq & {[\psi(z, z)-\psi(y, y)] \max \left\{G_{p}(x, x, x), G_{p}(y, y, y), G_{p}(z, z, z)\right\} } \\
& +\psi(x, y) \psi(x, z)\left[\phi(Q(x, y, z))-G_{p}(T x, T y, T z)\right]
\end{aligned}
$$

for all $x, y, z \in X$, where $\phi:[0, \infty) \rightarrow[0, \infty)$ is an upper semi-continuous from the right function such that $\phi(t)<t$ for all $t>0$. Then $T$ has a unique fixed point $z \in X$. Moreover, $G_{p}(z, z, z)=0$.

Proof Clearly, by taking $y=z$ in the hypothesis, we have

$$
G_{p}(T x, T y, T y) \leq \phi(Q(x, y, y))=\phi(M(x, y, y))
$$

for all $x, y \in X$. Then the conditions of Theorem 2.1 hold. This concludes the proof.

Example 2.1 Let $X=[0, \infty), G_{p}: X \times X \times X \rightarrow \mathbb{R}$ be defined by $G_{p}(x, y, z)=\max \{x, y, z\}$. Then $\left(X, G_{p}\right)$ is a GP-complete GP-metric space. Let $f: X \rightarrow X$ be defined by $T x=\frac{x}{2(x+1)}$ and $\psi(t)=\frac{t}{1+t}$ for all $t \in[0,+\infty)$.

Proof Without loss of generality, we assume that $x \geq y$. Then

$$
G_{p}(T x, T y, T y)=\frac{x}{2(x+1)} \leq \frac{x}{x+1}=\psi(x)=\psi\left(G_{p}(x, y, y)\right) .
$$

Then the condition of Theorem 2.1 holds and $T$ has a unique fixed point 0 in $[0, \infty)$. Moreover, $G_{p}(0,0,0)=0$.

Example 2.2 Let $X=[0, \infty), G_{p}: X \times X \times X \rightarrow \mathbb{R}$ be defined by $G_{p}(x, y, z)=\max \{x, y, z\}$. Then $\left(X, G_{p}\right)$ is a $G P$-complete $G P$-metric space. Let $T: X \rightarrow X$ be defined by

$$
T x= \begin{cases}\frac{1}{2} x^{2} & \text { if } 0 \leq x<1 / 3 \\ (1-x) / 2 & \text { if } 1 / 3 \leq x \leq 1 \\ \frac{1}{4} x & \text { if } x>1\end{cases}
$$

and $\psi(t)=\frac{1}{2} t$ for all $t \in[0,+\infty)$.

Proof To prove this example, we need to consider the following cases:

- Let $0 \leq x, y<1 / 3$. Then

$$
G_{p}(T x, T y, T y)=\frac{1}{2} \max \left\{x^{2}, y^{2}\right\} \leq \frac{1}{2} \max \{x, y\}=\psi\left(G_{p}(x, y, y)\right) .
$$

- Let $1 / 3 \leq x, y \leq 1$. Then

$$
G_{p}(T x, T y, T y)=\frac{1}{2} \max \{1-x, 1-y\} \leq \frac{1}{2} \max \{x, y\}=\psi\left(G_{p}(x, y, y)\right) .
$$


- Let $x, y>1$. Then

$$
G_{p}(T x, T y, T y)=\frac{1}{4} \max \{x, y\} \leq \frac{1}{2} \max \{x, y\}=\psi\left(G_{p}(x, y, y)\right) .
$$

- Let $0 \leq x<1 / 3$ and $1 / 3 \leq y \leq 1$. Then

$$
G_{p}(T x, T y, T y)=\max \left\{\frac{1}{2} x^{2},(1-y) / 2\right\} \leq \frac{1}{2} \max \{x, y\}=\psi\left(G_{p}(x, y, y)\right) .
$$

- Let $0 \leq x<1 / 3$ and $y>1$. Then

$$
G_{p}(T x, T y, T y)=\max \left\{\frac{1}{2} x^{2}, \frac{1}{4} y\right\} \leq \frac{1}{2} \max \{x, y\}=\psi\left(G_{p}(x, y, y)\right) .
$$

- Let $1 / 3 \leq x \leq 1$ and $y>1$. Then

$$
G_{p}(T x, T y, T y)=\max \left\{(1-x) / 2, \frac{1}{4} y\right\} \leq \frac{1}{2} \max \{x, y\}=\psi\left(G_{p}(x, y, y)\right) .
$$

Then the condition of Theorem 2.1 holds and $T$ has a unique fixed point 0 in $[0, \infty)$. Moreover, $G_{p}(0,0,0)=0$.

Lemma 2.3 Let $\phi:[0, \infty) \rightarrow[0, \infty)$ be nondecreasing and let $t>0$. If $\lim _{n \rightarrow \infty} \phi^{n}(t)=0$, then $\phi(t)<t$.

Theorem 2.2 Let $\left(X, G_{p}\right)$ be a GP-complete GP-metric space and $T: X \rightarrow X$ be a map such that

$$
G_{p}(T x, T y, T y) \leq \phi(N(x, y, y)),
$$

where $N(x, y, y)=\max \left\{G_{p}(x, y, y), G_{p}(x, T x, T x), G_{p}(y, T y, T y)\right\}$ for all $x, y \in X$, and $\phi$ : $[0, \infty) \rightarrow[0, \infty)$ is a nondecreasing function such that $\lim _{n \rightarrow \infty} \phi^{n}(t)=0$ for all $t>0$. Then $T$ has a unique fixed point $z \in X$. Moreover, $G_{p}(z, z, z)=0$.

Proof Let $x \in X$. If there is $n \in \mathbb{N}$ such that $T^{n} x=T^{n+1} x$, then $T^{n} x$ is a fixed point of $T$ and the uniqueness of $T^{n} x$ follows as in the last part of the proof below. Hence, we will assume that $T^{n} x \neq T^{n+1} x$ for all $n \in \mathbb{N}$. Put $x_{0}=x$ and construct the sequence $\left(x_{n}\right)_{n \in \mathbb{N}}$, where $x_{n}=T^{n} x_{0}$ for all $n \in \mathbb{N}$. Thus, $x_{n+1}=T x_{n}$ and $G_{p}\left(x_{n}, x_{n+1}, x_{n+1}\right)>0$ for all $n \in \mathbb{N}$. By Lemma 2.2(b),

$$
G_{p}\left(x_{n}, x_{n+1}, x_{n+1}\right) \leq \phi\left(G_{p}\left(x_{n-1}, x_{n}, x_{n}\right)\right)
$$

for all $n \in \mathbb{N}$. Then, since $\phi$ is nondecreasing, we deduce that

$$
G_{p}\left(x_{n}, x_{n+1}, x_{n+1}\right) \leq \phi^{n}\left(G_{p}\left(x_{0}, x_{1}, x_{1}\right)\right)
$$

for all $n \in \mathbb{N}$. Hence, $\lim _{n \rightarrow \infty} G_{p}\left(x_{n}, x_{n+1}, x_{n+1}\right)=0$. Now, choose an arbitrary $\varepsilon>0$. Since $\lim _{n \rightarrow \infty} \phi^{n}(\varepsilon)=0$, it follows from Lemma 2.3 that $\phi(\varepsilon)<\varepsilon$, so there is $n_{\varepsilon} \in \mathbb{N}^{*}$ such that

$$
G_{p}\left(x_{n}, x_{n+1}, x_{n+1}\right)<\varepsilon-\phi(\varepsilon)
$$


for all $n \geq n_{\varepsilon}$. Therefore,

$$
\begin{aligned}
G_{p}\left(x_{n}, x_{n+2}, x_{n+2}\right) & \leq G_{p}\left(x_{n}, x_{n+1}, x_{n+1}\right)+G_{p}\left(x_{n+1}, x_{n+2}, x_{n+2}\right) \\
& <\varepsilon-\phi(\varepsilon)+\phi\left(G_{p}\left(x_{n}, x_{n+1}, x_{n+1}\right)\right) \\
& \leq \varepsilon-\phi(\varepsilon)+\phi(\varepsilon)=\varepsilon
\end{aligned}
$$

for all $n \geq n_{\varepsilon}$. So,

$$
\begin{aligned}
G_{p}\left(x_{n}, x_{n+3}, x_{n+3}\right) & \leq G_{p}\left(x_{n}, x_{n+1}, x_{n+1}\right)+G_{p}\left(x_{n+1}, x_{n+3}, x_{n+3}\right) \\
& <\varepsilon-\phi(\varepsilon)+\phi\left(N\left(x_{n}, x_{n+2}, x_{n+2}\right)\right) \\
& \leq \varepsilon-\phi(\varepsilon)+\phi(\varepsilon)=\varepsilon,
\end{aligned}
$$

and following this process,

$$
G_{p}\left(x_{n}, x_{n+k}, x_{n+k}\right)<\varepsilon
$$

for all $n \geq n_{\varepsilon}$ and $k \in \mathbb{N}^{*}$. Consequently,

$$
\lim _{n, m \rightarrow \infty} G_{p}\left(x_{n}, x_{m}, x_{m}\right)=0,
$$

and thus $\left\{x_{n}\right\}_{n \in \mathbb{N}}$ is a Cauchy sequence in the $G_{p}$-complete $G_{p}$-metric space $\left(X, G_{p}\right)$. Hence, there is $z \in X$ such that

$$
0=\lim _{n, m \rightarrow \infty} G_{p}\left(x_{n}, x_{m}, x_{m}\right)=\lim _{n \rightarrow \infty} G_{p}\left(z, x_{n}, x_{n}\right)=G_{p}(z, z, z) .
$$

We show that $z$ is a fixed point of $T$. Assume the contrary. Then $G_{p}(z, T z, T z)>0$. For each $n \in \mathbb{N}^{*}$, we have

$$
\begin{aligned}
G_{p}(z, T z, T z) & \leq G_{p}\left(z, x_{n}, x_{n}\right)+G_{p}\left(x_{n}, T z, T z\right) \\
& \leq G_{p}\left(z, x_{n}, x_{n}\right)+\phi\left(N\left(z, z, x_{n-1}\right)\right) .
\end{aligned}
$$

From our assumption that $G_{p}(z, T z, T z)>0$, it easily follows that there is $n_{0} \in \mathbb{N}$ such that $N\left(z, z, x_{n-1}\right)=G_{p}(z, T z, T z)$ for all $n \geq n_{0}$. So,

$$
G_{p}(z, T z, T z) \leq G_{p}\left(z, x_{n}, x_{n}\right)+\phi\left(G_{p}(z, T z, T z)\right)
$$

for all $n \geq n_{0}$. Taking limits as $n \rightarrow \infty$, we obtain that

$$
G_{p}(z, T z, T z) \leq \phi\left(G_{p}(z, T z, T z)\right)<G_{p}(z, T z, T z),
$$

a contradiction. Consequently, $z=T z$. Finally, the uniqueness of $z$ follows as in Theorem 2.1. 
Example 2.3 Let $X=[0,1], G_{p}: X \times X \times X \rightarrow \mathbb{R}$ be defined by $G_{p}(x, y, z)=\max \{x, y, z\}$. Then $\left(X, G_{p}\right)$ is a $G P$-complete $G P$-metric space. Let $T: X \rightarrow X$ be defined by

$$
T x=\left(x^{2}-x^{4}\right) / 8
$$

and $\psi(t)=\frac{1}{4} t^{2}$ for all $t \in[0,+\infty)$.

Proof Without loss of generality, we assume that $x \geq y$. Then

$$
N(x, y, y)=\max \left\{G_{p}(x, y, y), G_{p}(x, T x, T x), G_{p}(y, T y, T y)\right\}=x .
$$

And so

$$
\begin{aligned}
G_{p}(T x, T y, T y) & =\max \left\{\left(x^{2}-x^{4}\right) / 8,\left(y^{2}-y^{4}\right) / 8\right\} \\
& =\max \left\{\frac{\left(x-x^{2}\right)\left(x+x^{2}\right)}{8}, \frac{\left(y-y^{2}\right)\left(y+y^{2}\right)}{8}\right\} \\
& \leq \max \left\{\frac{x\left(x-x^{2}\right)}{4}, \frac{y\left(y-y^{2}\right)}{4}\right\} \\
& \leq \frac{1}{4} \max \left\{x^{2}, y^{2}\right\}=\frac{1}{4} x^{2}=\psi(N(x, y, y)) .
\end{aligned}
$$

Then the condition of Theorem 2.2 holds and $T$ has a unique fixed point 0 in $[0,1]$. Moreover, $G_{p}(0,0,0)=0$.

Example 2.4 Let $X=[0, \infty), G_{p}: X \times X \times X \rightarrow \mathbb{R}$ be defined by $G_{p}(x, y, z)=\max \{x, y, z\}$. Then $\left(X, G_{p}\right)$ is a $G P$-complete $G P$-metric space. Let $T: X \rightarrow X$ be defined by

$$
T x= \begin{cases}\frac{1}{4}\left(x^{2}+x\right) & \text { if } 0 \leq x<1 \\ \frac{1}{8} x & \text { if } x \geq 1\end{cases}
$$

and $\psi(t)=\frac{1}{2} t$ for all $t \in[0,+\infty)$.

Proof To prove this example, we need to examine the following cases:

- Let $0 \leq x, y<1$. Then $N(x, y, y)=\max \{x, y\}$ and

$$
G_{p}(T x, T y, T y)=\max \left\{\frac{1}{4}\left(x^{2}+x\right), \frac{1}{4}\left(y^{2}+y\right)\right\} \leq \frac{1}{2} \max \{x, y\}=\psi(N(x, y, y)) .
$$

- Let $x, y \geq 1$. Then $N(x, y, y)=\max \{x, y\}$ and

$$
G_{p}(T x, T y, T y)=\frac{1}{8} \max \{x, y\} \leq \frac{1}{2} \max \{x, y\}=\psi(N(x, y, y)) .
$$

- Let $0 \leq x<1$ and $y \geq 1$. Then $N(x, y, y)=y$ and

$$
G_{p}(T x, T y, T y)=\max \left\{\frac{1}{4}\left(x^{2}+x\right), \frac{1}{8} y\right\} \leq \frac{1}{2} \max \{x, y\}=\frac{1}{2} y=\psi(N(x, y, y)) .
$$


Then the condition of Theorem 2.2 holds and $T$ has a unique fixed point 0 in $[0,1]$. Moreover, $G_{p}(0,0,0)=0$.

Corollary 2.2 Let $\left(X, G_{p}\right)$ be a GP-complete GP-metric space and $T: X \rightarrow X$ be a map such that

$$
G_{p}(T x, T y, T z) \leq \phi(N(x, y, z))
$$

where $N(x, y, y)=\max \left\{G_{p}(x, y, z), G_{p}(x, T x, T x), G_{p}(y, T y, T y), G_{p}(z, T z, T z)\right\}$ for all $x, y \in X$, and $\phi:[0, \infty) \rightarrow[0, \infty)$ is a nondecreasing function such that $\lim _{n \rightarrow \infty} \phi^{n}(t)=0$ for all $t>0$. Then $T$ has a unique fixed point $z \in X$. Moreover, $G_{p}(z, z, z)=0$.

Similarly, we have the corollary below.

Corollary 2.3 Let $\left(X, G_{p}\right)$ be a GP-complete GP-metric space and $T: X \rightarrow X$ be a map such that

$$
\begin{aligned}
0 \leq & {[\psi(z, z)-\psi(y, y)] \max \left\{G_{p}(x, x, x), G_{p}(y, y, y), G_{p}(z, z, z)\right\} } \\
& +\psi(x, y) \psi(x, z)\left[\phi(R(x, y, z))-G_{p}(T x, T y, T z)\right],
\end{aligned}
$$

where $R(x, y, z)=\max \left\{G_{p}(x, y, z), G_{p}(x, T x, T x), G_{p}(y, T y, T y), G_{p}(z, T z, T z)\right\}$ for all $x, y, z \in X$, and $\phi:[0, \infty) \rightarrow[0, \infty)$ is a nondecreasing function such that $\lim _{n \rightarrow \infty} \phi^{n}(t)=0$ for all $t>0$. Then $T$ has a unique fixed point $z \in X$. Moreover, $G_{p}(z, z, z)=0$.

In [46], Jachymski proved the equivalence of auxiliary functions (see Lemma 1). Inspired by the results from this remarkable paper of Jachymski, we finish this paper by stating the following theorem.

Theorem 2.3 (See [46]) Let $\left(X, G_{p}\right)$ be a GP-complete GP-metric space and $T: X \rightarrow X$ be a self-mapping. Assume that

$$
\begin{aligned}
M(x, y, y)= & \max \left\{G_{p}(x, y, y), G_{p}(x, T x, T x), G_{p}(y, T y, T y),\right. \\
& \left.\frac{1}{2}\left[G_{p}(x, T y, T y)+G_{p}(y, T x, T x)\right]\right\} .
\end{aligned}
$$

Then the following statements are equivalent:

(i) there exist functions $\psi, \eta \in \Psi$ such that

$$
\psi(G(T x, T y, T y)) \leq \psi(M(x, y, y))-\eta(M(x, y, y))
$$

for any $x, y \in X$

(ii) there exists a function $\beta:[0, \infty) \rightarrow[0,1]$ such that for any bounded sequence $\left\{t_{n}\right\}$ of positive reals, $\beta\left(t_{n}\right) \rightarrow 1$ implies $t_{n} \rightarrow 0$ and

$$
G(T x, T y, T y) \leq \beta(M(x, y, y)) \psi(M(x, y, y))
$$

for any $x, y \in X$; 
(iii) there exists a continuous function $\eta:[0, \infty) \rightarrow[0, \infty)$ such that $\eta^{-1}(\{0\})=0$ and

$$
G(T x, T y, T y) \leq M(x, y, y)-\eta(M(x, y, y))
$$

for any $x, y \in X$

(iv) there exist a function $\psi \in \Psi$ and a nondecreasing, right-continuous function $\varphi:[0, \infty) \rightarrow[0, \infty)$ with $\varphi(t)<t$ and for all $t>0$ with

$$
\psi(G(T x, T y, T y)) \leq \varphi(\psi(M(x, y, y)))
$$

for any $x, y \in X$

(v) there exists a continuous and nondecreasing function $\varphi:[0, \infty) \rightarrow[0, \infty)$ such that $\varphi(t)<t$ and for all $t>0$ with

$$
\psi(G(T x, T y, T y)) \leq \varphi(M(x, y, y))
$$

for any $x, y \in X$.

\section{Competing interests}

The authors declare that they have no competing interests.

\section{Authors' contributions}

All authors read and approved the final manuscript.

\section{Author details}

'Department of Mathematics, Institute of Science and Technology, Gazi University, Ankara, 06500, Turkey. ${ }^{2}$ Department of Mathematics, Atilim University, Incek, Ankara 06836, Turkey. ${ }^{3}$ Department of Mathematics, Sahand University of Technology, Tabriz, Iran.

\section{Received: 8 November 2012 Accepted: 23 January 2013 Published: 6 February 2013}

\section{References}

1. Banach, S: Sur les opérations dans les ensembles abstraits et leur application aux équations intégrales. Fundam. Math. 3, 133-181 (1922)

2. Matthews, SG: Partial metric topology. In: Proc. 8th Summer Conference on General Topology and Applications. Ann. New York Acad. Sci., vol. 728, pp. 183-197 (1994)

3. Ćirić, LJ, Samet, B, Aydi, H, Vetro, C: Common fixed points of generalized contractions on partial metric spaces and an application. Appl. Math. Comput. 218, 2398-2406 (2011)

4. Di Bari, C, Milojević, M, Radenović, S, Vetro, P: Common fixed points for self-mappings on partial metric spaces. Fixed Point Theory Appl. 2012, Article ID 140 (2012)

5. Ilić, D, Pavlović, V, Rakocević, V: Some new extensions of Banach's contraction principle to partial metric space. Appl. Math. Lett. 24, 1326-1330 (2011)

6. Karapinar, E, Erhan, IM: Fixed point theorems for operators on partial metric spaces. Appl. Math. Lett. 24, 1900-1904 (2011)

7. Karapinar, E: Generalizations of Caristi Kirk's theorem on partial metric spaces. Fixed Point Theory Appl. 2011, Article ID 4 (2011)

8. Karapinar, E: A note on common fixed point theorems in partial metric spaces. Miskolc Math. Notes 12, 185-191 (2011)

9. Karapinar, E: Some fixed point theorems on the class of comparable partial metric spaces on comparable partial metric spaces. Appl. Gen. Topol. 12, 187-192 (2011)

10. Karapinar, E: Ćirić types nonunique fixed point theorems on partial metric spaces. J. Nonlinear Sci. Appl. 5, 74-83 (2012)

11. Karapinar, E: Weak $\phi$-contraction on partial metric spaces. J. Comput. Anal. Appl. 14, $206-210$ (2012)

12. Karapinar, E, Shobkolaei, N, Sedghi, S, Vaezpour, SM: A common fixed point theorem for cyclic operators on partial metric spaces. Filomat 26, 407-414 (2012)

13. Karapinar, E, Erhan, I, Ulus, AY: Fixed point theorem for cyclic maps on partial metric spaces. Appl. Math. Inf. Sci. 6(1), 239-244 (2012)

14. Nashine, HK, Kadelburg, Z, Radenović, S: Common fixed point theorems for weakly isotone increasing mappings in ordered partial metric spaces. Math. Comput. Model. (2011). doi:10.1016/j.mcm.2011.12.019 
15. Kopperman, R, Matthews, SG, Pajoohesh, H: What do partial metrics represent? In: Spatial Representation: Discrete vs. Continuous Computational Models. Dagstuhl Seminar Proceedings, vol. 04351. Internationales Begegnungs- und Forschungszentrum für Informatik (IBFI), Schloss Dagstuhl, Wadern (2005)

16. Oltra, S, Valero, O: Banach's fixed point theorem for partial metric spaces. Rend. Ist. Mat. Univ. Trieste 36, 17-26 (2004)

17. O'Neill, SJ: Two topologies are better than one. Technical report, University of Warwick, Coventry (1995)

18. Romaguera, S: Fixed point theorems for generalized contractions on partial metric spaces. Topol. Appl. 159, 194-199 (2012)

19. Romaguera, S: Matkowski's type theorems for generalized contractions on (ordered) partial metric spaces. Appl. Gen. Topol. 12, 213-220 (2011)

20. Romaguera, S, Schellekens, M: Partial metric monoids and semivaluation spaces. Topol. Appl. 153, $948-962$ (2005)

21. Romaguera, S, Valero, O: A quantitative computational model for complete partial metric spaces via formal balls. Math. Struct. Comput. Sci. 19, 541-563 (2009)

22. Schellekens, MP: A characterization of partial metrizability: domains are quantifiable. Theor. Comput. Sci. 305, 409-432 (2003)

23. Abedelljawad, T, Karapınar, E, Taş, K: Existence and uniqueness of common fixed point on partial metric spaces. Appl. Math. Lett. 24, 1894-1899 (2011)

24. Altun, I, Sola, F, Simsek, H: Generalized contractions on partial metric spaces. Topol. Appl. 157, $2778-2785$ (2010)

25. Altun, I, Erduran, A: Fixed point theorems for monotone mappings on partial metric spaces. Fixed Point Theory Appl. 2011, Article ID 508730 (2011)

26. Aydi, H: Some coupled fixed point results on partial metric spaces. Int. J. Math. Math. Sci. 2011, Article ID 647091 (2011)

27. Aydi, H: Some fixed point results in ordered partial metric spaces. J. Nonlinear Sci. Appl. 4(2), 1-15 (2011)

28. Mustafa, Z, Sims, B: A new approach to generalized metric spaces. J. Nonlinear Convex Anal. 7(2), $289-297$ (2006)

29. Mustafa, Z, Sims, B: Some remarks concerning D-metric spaces. In: Proceedings of the International Conferences on Fixed Point Theory and Applications, Valencia, Spain, July 2003, pp. 189-198 (2003)

30. Mustafa, Z: A new structure for generalized metric spaces with applications to fixed point theory. Ph.D. Thesis, The University of Newcastle, Callaghan, Australia (2005)

31. Mustafa, Z, Obiedat, H, Awawdeh, F: Some fixed point theorem for mappings on complete G-metric spaces. Fixed Point Theory Appl. 2008, Article ID 189870 (2008)

32. Mustafa, Z, Shatanawi, W, Bataineh, F: Existence of fixed point results in G-metric spaces. Int. J. Math. Math. Sci. 2009 Article ID 283028 (2009)

33. Mustafa, Z, Obiedat, H: A fixed point theorem of Reich in G-metric spaces. CUBO 12(1), 83-93 (2010)

34. Mustafa, Z, Sims, B: Fixed point theorems for contractive mappings in complete G-metric spaces. Fixed Point Theory Appl. 2009, Article ID 917175 (2009). doi:10.1155/2009/917175

35. Mustafa, Z, Khandagjy, M, Shatanawi, W: Fixed point results on complete G-metric spaces. Studia Sci. Math. Hung. 48(3), 304-319 (2011)

36. Mustafa, Z, Awawdeh, F, Shatanawi, W: Fixed point theorem for expansive mappings in G-metric spaces. Int. J. Contemp. Math. Sci. 5(49-52), 2463-2472 (2010)

37. Mustafa, Z, Aydi, H, Karapınar, E: On common fixed points in G-metric spaces using (E.A) property. Comput. Math. Appl. (2012). doi:10.1016/j.camwa.2012.03.051

38. Mustafa, Z, Aydi, H, Karapınar, E: Mixed g-monotone property and quadruple fixed point theorems in partially ordered metric spaces. Fixed Point Theory Appl. 2012, Article ID 71 (2012)

39. Saadati, R, Vaezpour, SM, Vetro, P, Rhoades, BE: Fixed point theorems in generalized partially ordered G-metric spaces. Math. Comput. Model. 52, 797-801 (2010)

40. Shatanawi, W: Fixed point theory for contractive mappings satisfying $\Phi$-maps in $G$-metric spaces. Fixed Point Theory Appl. 2010, Article ID 181650 (2010)

41. Shatanawi, W: Some fixed point theorems in ordered G-metric spaces and applications. Abstr. Appl. Anal. 2011, Article ID 126205 (2011)

42. Valero, O: On Banach fixed point theorems for partial metric spaces. Appl. Gen. Topol. 6(2), 229-240 (2005)

43. Zand, MRA, Nezhad, AD: A generalization of partial metric spaces. J. Contemp. Appl. Math. 24, 86-93 (2011)

44. Abbas, M, Khan, AR, Nazir, T: Coupled common fixed point results in two generalized metric spaces. Appl. Math. Comput. 217, 6328-6336 (2011)

45. Aydi, H, Karapinar, E, Salimi, P: Some fixed point results in GP-metric spaces. J. Appl. Math. 2012, Article ID 891713 (2012)

46. Jachymski, J: Equivalent conditions for generalized contractions on (ordered) metric spaces. Nonlinear Anal. 74, 768-774 (2011)

doi:10.1186/1029-242X-2013-39

Cite this article as: Bilgili et al.: Fixed point theorems for generalized contractions on GP-metric spaces. Journal of Inequalities and Applications 2013 2013:39. 